\title{
Optimization of nanolime solvent for the consolidation of coarse porous limestone
}

\author{
Giovanni Borsoi ${ }^{1}$ - Barbara Lubelli ${ }^{1,2} \cdot$ Rob van Hees $^{1,2} \cdot$ Rosário Veiga $^{3} \cdot$ \\ António Santos Silva ${ }^{4}$
}

Received: 11 July 2016/ Accepted: 17 August 2016/Published online: 25 August 2016

(c) The Author(s) 2016. This article is published with open access at Springerlink.com

\begin{abstract}
The potentialities of nanomaterials for application in the field of conservation have been widely investigated in the last two decades. Among nanomaterials, nanolimes, i.e., dispersions of lime nanoparticles in alcohols are promising consolidating products for calcareous materials. Nanolimes are effective in recovering the very superficial loss of cohesion of decayed materials, but they do not always provide sufficient mass consolidation. This limitation is mainly related to the deposition of the nanoparticles nearby the surface of the material. Experimental research has been set up with the aim of improving the in-depth deposition of lime nanoparticles. Previous research by the authors has shown that nanolime deposition within a substrate can be controlled by adapting the nanolimes properties (kinetic stability and evaporation rate) to the moisture transport behavior of the substrate. Nanolime properties can be modified by the use of different solvents. In this research, nanolime dispersions have been further optimized for application on Maastricht limestone, a coarse porous limestone. Firstly, nanolimes were synthesized and dispersed in ethanol and/or water, both pure and mixed in different percentages. Subsequently, based on the kinetic stability of the nanolime dispersions, the most
\end{abstract}

Giovanni Borsoi

G.Borsoi@tudelft.nl

1 Heritage and Architecture Section, Faculty of Architecture, TU Delft, Julianalaan 134, 2628 BL Delft, The Netherlands

2 Division of Structural Reliability, TNO, Van Mourik Broekmanweg 6, 2628 XE Delft, The Netherlands

3 Building Division, LNEC, Av. do Brasil 101, 1700-066 Lisbon, Portugal

4 Materials Division, LNEC, Av. do Brasil 101, 1700-066 Lisbon, Portugal promising solvent mixtures were selected and applied on the limestone. The deposition of lime nanoparticles within the limestone was studied by phenolphthalein test, optical microscopy and scanning electron microscopy. The results confirm that nanolime dispersed in a mixture of ethanol $(95 \%)$ and water $(5 \%)$ can guarantee a better nanoparticles in-depth deposition within coarse porous substrates, when compared to dispersions in pure ethanol.

\section{Introduction}

The application of nanotechnology in the field of conservation Science has remarkably increased over the last two decades. Several nanomaterials with cleaning, consolidating and/or protective properties have been developed for the conservation of artworks [1-3]. Among nanomaterials, nanolime attracted an increasing interest, due to its potential as consolidating product for calcareous materials, such as frescos, limestones and lime-based renders and plasters. Nanolimes are colloidal alcoholic dispersions of calcium hydroxide nanoparticles, with spherical to hexagonal shape and a size ranging from 50 to $600 \mathrm{~nm}$ [4-8]. Thanks to the nano to submicrometric size of the particles and to the alcoholic solvent, nanolimes have a high reactivity and a high lime concentration, which provide a better consolidating effect than traditional lime-based consolidants (e.g., limewater) $[9,10]$. Besides, nanolimes have a better compatibility and durability on calcareous substrates than TEOS-based products (e.g., ethyl silicate), which are commonly used for stone consolidation [11-14].

Concerning their consolidation effectiveness, nanolimes have proven to work properly for the pre-consolidation and for the recovery of the superficial cohesion of different materials, such as mural paintings, plasters, paper and 
wood. [4, 5, 8-10, 15, 16]. However, when mass consolidation is required, e.g., in the case of decayed renders or limestone, nanolimes often show a poor effectiveness and sometimes result in the formation of a white haze on the surface [17, 18]. An important reason for their limited effectiveness is related to deposition of nanoparticles at the surface, resulting in a poor consolidating effect in depth [18-21].

Previous research has shown that, depending on the moisture transport properties of the substrate, surface deposition may occur not only during absorption but also during evaporation of the solvent, due to a partial back migration of the nanoparticles to the surface [19]. This suggests that the approach proposed by the authors in [22], i.e., tailoring the kinetic stability and the evaporation rate of nanolime (by modification of the solvent) to the moisture transport properties of the substrate to be treated, can improve nanoparticles in-depth deposition within the substrate. According to this approach, dispersions with lower kinetic stability and higher drying rate should be preferred for application on substrates with very fast moisture transport properties, as they limit back migration of nanoparticles during drying and thereby improve in-depth deposition.

In the research described in this article, this approach has been optimized and validated for Maastricht limestone, a highly and coarse porous limestone.

Lime nanoparticles were synthesized and dispersed in ethanol, water and in mixtures of these two solvents; the kinetic stability (Sect. 3.2) of the dispersions was measured; based on these data, nanolimes dispersed in pure ethanol or in a mixed ethanol-water solvent were selected (Sect. 3.3) and applied on Maastricht limestone (Sect. 3.1). Finally, the in-depth deposition of the lime nanoparticles within the limestone was assessed (Sect. 3.4).

\section{Materials and methods}

\subsection{Maastricht limestone}

The Maastricht limestone is a soft, yellowish limestone $\left(\approx 95 \% \mathrm{CaCO}_{3}\right)[23,24]$, quarried in the Belgian and Dutch provinces of Limburg and used as building material in the same regions.

Despite its low mechanical strength, Maastricht limestone has generally shown a good durability, probably related to the dissolution and re-precipitation of carbonates within the pore network of the stone, when exposed to atmospheric agents [25]. However, Maastricht limestone may in some cases show decay in the form of loss of cohesion at the surface (e.g., powdering, scaling) [26].

\subsubsection{Porosity and pore size distribution}

The open porosity and the pore size distribution of Maastricht limestone was assessed by means of mercury intrusion porosimetry (MIP). An Autopore IV9500 (Micromeritics) was used to obtain porosity data. Pores in the range $0.01-400 \mu \mathrm{m}$ could be measured with this instrument. A contact angle of $141^{\circ}$ was assumed between mercury and the stone. An equilibration time of $30 \mathrm{~s}$ was used between each pressure increase step.

\subsubsection{Specimens}

Cylindrical specimens (diameter: $4 \mathrm{~cm}$, height: $4 \mathrm{~cm}$ ) were used in this research. Specimens were drilled from sound Maastricht limestone blocks, with an orientation perpendicular to the limestone bedding. Before testing, specimens were dried in the oven at $60{ }^{\circ} \mathrm{C}$ for $24 \mathrm{~h}$ and then conditioned at $20{ }^{\circ} \mathrm{C}$ and $50 \% \mathrm{RH}$.

\subsubsection{Absorption and drying kinetics}

The capillary absorption of water and ethanol in the Maastricht limestone specimens was measured according to EN 15801 [27]. A grid was placed in a Petri dish, which was subsequently filled with water or ethanol. The core specimens, sealed with Parafilm M (by Bemis NA, USA) on the lateral sides, were placed with their bottom surface on the grid. During the absorption process, the specimen weight was measured till saturation was reached.

The drying rate of the specimens, saturated with water or ethanol, was evaluated by measuring the weight loss over time, in accordance with EN 16322 [28].

The absorption and drying tests were carried out in threefold and performed under controlled conditions (50\% $\mathrm{RH}, \quad T=20^{\circ} \mathrm{C}$, air speed $<0.1 \mathrm{~m} / \mathrm{s}$ ). Water, ethanol absorption and drying were carried out in sequence on the same specimens, in order to minimize the effect of the stone variability.

\subsection{Nanolime}

\subsubsection{Synthesis and solvent selection}

Nanolimes were synthesized by solvothermal reaction of metallic calcium in water. Metallic granular calcium (p.a. $99 \%$, by Sigma-Aldrich) was stirred for few hours in distilled water (conductivity $<2 \mu \mathrm{s} / \mathrm{cm}$ ) within a reactor at $T=90{ }^{\circ} \mathrm{C}$. The aqueous medium was then substituted by centrifuging the colloidal dispersions using an Eppendorf Centrifuge 5810R (rotation speed $8000 \mathrm{rpm}, T=10 \mathrm{~min}$ ), in order to obtain colloidal dispersions with an equivalent concentration of $25 \mathrm{~g} / \mathrm{l}$. The supernatant was subsequently 
Table 1 Physical-chemical properties of the selected solvents at $T=20{ }^{\circ} \mathrm{C}$ [29]

\begin{tabular}{llllll}
\hline Solvent & $\begin{array}{l}\text { Density } \\
\left(\mathrm{g} / \mathrm{cm}^{3}\right)\end{array}$ & $\begin{array}{l}\text { Dynamic } \\
\text { viscosity } \\
(\mathrm{mPa} \mathrm{s})\end{array}$ & $\begin{array}{l}\text { Boiling } \\
\text { point }\left({ }^{\circ} \mathrm{C}\right)\end{array}$ & $\begin{array}{l}\text { Dielectric } \\
\text { constant }\end{array}$ & $\begin{array}{l}\text { Surface tension } \\
\text { (solvent/air) }(\mathrm{N} / \mathrm{m})\end{array}$ \\
\hline Ethanol & 0810 & 1214 & 78.37 & 24.6 & 0.0221 \\
Water & 1000 & 1002 & 99.61 & 80.4 & 0.0728 \\
\hline
\end{tabular}

extracted through glass volumetric pipettes and substituted by ethanol (p.a. $99.5 \%$ by Sigma-Aldrich), fresh distilled water (conductivity $<2 \mu \mathrm{s} / \mathrm{cm}$ ) or mixtures of these solvents.

Ethanol and water were selected as solvents based on the results obtained in previous works [19, 22]. Ethanol is a highly volatile solvent and guarantees a high kinetic stability to the dispersion, whereas water has a higher boiling point and higher surface tension, which results in a low kinetic stability (Table 1).

Next to pure ethanol and water dispersion, ethanol-based dispersions mixed with different percentages of water (5-20-50-80\%) were prepared as well (Table 2). The addition of a percentage of water with the dispersion is expected to decrease the kinetic stability. The aim was to produce dispersions with a moderate stability that can guarantee a homogenous absorption with the substrate, but at the same time limit back migration of nanoparticles to the surface during drying. In other words, when the desired absorption depth is reached, the kinetic stability should decrease and favor nanolime precipitation in depth.

\subsubsection{Kinetic stability}

The kinetic stability of the nanolimes was determined by turbidity measurements, analyzing their absorbance at $\lambda=600 \mathrm{~nm}$ by a UV-Vis spectroscopy (UVmini-1240 UVVis Spectrophotometer, by Shimadzu). Before the analysis, the nanolimes were placed in an ultrasonic bath $(60 \mathrm{~Hz}$, by VWR symphony Ultrasonic Cleaners) for $60 \mathrm{~min}$, in order to minimize nanoparticle aggregation phenomena. The absorbance at $600 \mathrm{~nm}$ was considered as the parameter proportional to the turbidity of the dispersion; its decrease as a function of time is due to particle agglomeration and settling. Before measurement, the nanolimes were placed in an ultrasonic bath $(60 \mathrm{~Hz}$, by VWR symphony Ultrasonic Cleaners) for $60 \mathrm{~min}$, to minimize nanoparticle aggregation phenomena; afterward, nanolimes were placed in $10 \mathrm{~mm}$ path length plastic cuvettes, which were capped during measurements to avoid solvent evaporation.

The relative kinetic stability parameter (KS \%) of the dispersions, defined as the ratio of the optical density of the supernatant liquid (i.e., saturated $\mathrm{Ca}(\mathrm{OH})_{2}$ solution) and of the original dispersion determined at $600 \mathrm{~nm}$, was calculated using the following formula:
Table 2 Acronyms and solvent composition of the nanolime dispersions considered in this work

\begin{tabular}{ll}
\hline Nanolime acronym & Solvent mixture (in volume) \\
\hline $\mathrm{H} 100$ & $100 \% \mathrm{H}_{2} \mathrm{O}$ \\
E20H80 & $20 \% \mathrm{EtOH}, 80 \% \mathrm{H}_{2} \mathrm{O}$ \\
E50H50 & $50 \% \mathrm{EtOH}, 50 \% \mathrm{H}_{2} \mathrm{O}$ \\
E80H20 & $80 \% \mathrm{EtOH}, 20 \% \mathrm{H}_{2} \mathrm{O}$ \\
E95H5 & $95 \% \mathrm{EtOH}, 5 \% \mathrm{H}_{2} \mathrm{O}$ \\
E100 & $100 \% \mathrm{EtOH}$
\end{tabular}

$\mathrm{EtOH}$ ethanol, $\mathrm{H}_{2} \mathrm{O}$ water

$\mathrm{KS} \%=1-\left[\left(A_{0}-A_{t}\right) / A_{0}\right] \times 100$

where $A_{0}$ starting absorbance at $600 \mathrm{~nm}$ and $A_{t}$ absorbance at a given time at $600 \mathrm{~nm} \mathrm{[5].}$

\subsubsection{Application and assessment of nanolime deposition}

Nanolimes E80H20 and E95H5, selected on the basis of the result of the kinetic stability measurements (Sect. 3.3), were applied on the Maastricht limestone specimens by capillary absorption until full saturation. E100 was applied as well for comparison. The bottom surface of the specimens was partially immersed in a Petri dish filled with nanolime and with a grid on the bottom. The wetting front was visually monitored during absorption (Fig. 1).

Immediately after saturation, the specimens were broken with hammer and chisel in two halves: On one side, the wetting front of the dispersion was visually checked, and on the other side, the distribution of the lime nanoparticles was assessed by phenolphthalein test. This test consists in nebulizing a phenolphthalein solution $(1 \%$ phenolphthalein in $60 \%$ ethanol $/ 40 \%$ water) on the fresh crosssection of the specimen and observing the change in color. Phenolphthalein alcoholic solution is a well-known $\mathrm{pH}$ indicator which remains uncolored for $\mathrm{pH}<8.2$, while $\mathrm{pH}$ conditions higher than 9.8 lead to a purple color change [30]. In this case, a purple color of the substrate indicates the presence of nanolime $\left(\mathrm{pH}_{\mathrm{Ca}(\mathrm{OH}) 2}>11\right)$. By comparing the results of the phenolphthalein test with the macroscopical observations of the wetting front, separation of the nanoparticles from the solvent during absorption can be assessed. 


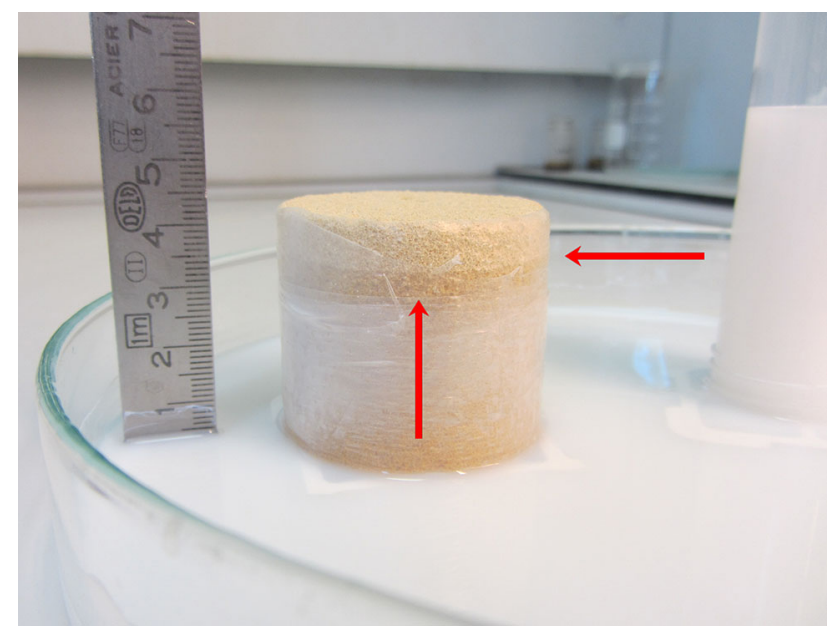

Fig. 1 Nanolime application by capillary absorption until full saturation; the red arrows indicate the wetting front and the homogeneous capillary rising of the nanolime

The deposition of nanolime in the stone after drying was assessed by optical and Scanning Electron Microscope. In order to be sure of the full carbonation of the lime nanoparticles [31], the specimens were stored at $50 \% \mathrm{RH}$ and $T=20{ }^{\circ} \mathrm{C}$ for at least 4 weeks before microscopy observations.

The drying surface and the cross-section of the specimens were observed by stereomicroscope Zeiss Stemi SV 11. Images were recorded with a Zeiss AxioCam MRc5 digital microscopy camera. The AxioVision 4.8 software and its interactive measurement tools were used to record and analyze the specimens.

Cross-sections were also studied by Scanning Electron Microscope equipped with energy-dispersive X-ray spectroscopy (SEM-EDS). The equipment used (Nova NanoSEM 650, by FEI) is coupled with a low vacuum solid-state detector BSED (GAD) that allows high resolution imaging (up to $1.4 \mathrm{~nm}$ ) and a high flexibility of the working conditions $(1-30 \mathrm{kV})$.

\section{Results}

\subsection{Substrate characterization}

\subsubsection{Porosity and pore size distribution}

Figure 2 shows the total open porosity and the pore size distribution of the Maastricht limestone. The Maastricht limestone has a very high porosity $(50 \%)$ and an unimodal pore size distribution, with macro pores $(30-50 \mu \mathrm{m})$.

Because of its high and coarse porosity, Maastricht limestone is expected to quickly absorb large amounts of nanolime dispersions, guarantying the penetration of the lime nanoparticles.

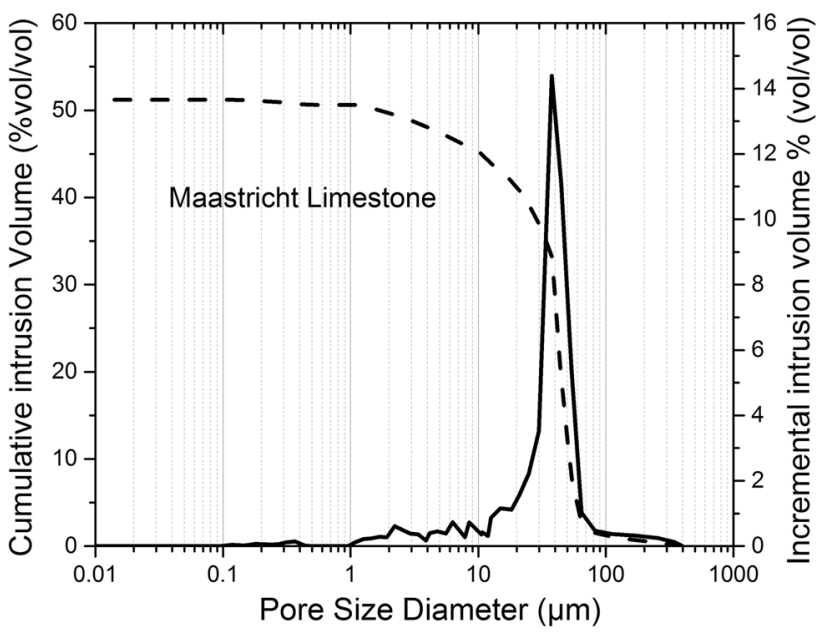

Fig. 2 Pore size distribution (solid) and total porosity (dotted) by MIP of Maastricht limestone

\subsubsection{Absorption and drying kinetics}

Figure 3a reports the absorption kinetics of ethanol and water on Maastricht limestone. As seen, the absorption of $\mathrm{H}_{2} \mathrm{O}$ is faster compared to that of ethanol, due to the higher surface tension of water (see Table 1).

When observing the drying kinetics (Fig. 3b), EtOH evaporates faster compared to $\mathrm{H}_{2} \mathrm{O}: \mathrm{EtOH}$ completely evaporates in $48-72 \mathrm{~h}$, whereas $\mathrm{H}_{2} \mathrm{O}$ takes $7-8$ days. This can be explained by the lower boiling point of ethanol; in addition, the higher surface tension of water enhances its retention within the pore network, delaying the drying rate.

\subsection{Nanolimes kinetic stability}

The kinetic stability of nanolime dispersions (Table 2) was evaluated by UV-Vis spectroscopy, by monitoring the absorbance of the dispersions at $600 \mathrm{~nm}$ (Fig. 4).

The aqueous dispersions (H100) showed a rapid drop in the absorbance, indicating a very low kinetic stability: Lime nanoparticles tend to settle rapidly, with a complete deposition within a few hours. The relative kinetic stability (KS \%) for $\mathrm{H} 100$ is less than $40 \%$ at $4 \mathrm{~h}$ from the preparation of the dispersion, and around $25 \%$ at $8 \mathrm{~h}$, indicating that most of the nanoparticles have settled at this time. The aggregation phenomena observed for H100 are most probably caused by short-range (attractive) Van der Waals forces [32, 33].

Differently, E100 shows high kinetic stability, with a slow and constant decrease in the absorbance over time (KS \% at 24 and $96 \mathrm{~h}$ is, respectively, 91 and $82 \%$ ). This behavior can be explained by the ethanol adsorption onto $\mathrm{Ca}(\mathrm{OH})_{2}$ nanoparticles, which subsequently acquire a similar electrical charge [5]. The repulsive electrostatic forces between nanoparticles decrease the frequency of 

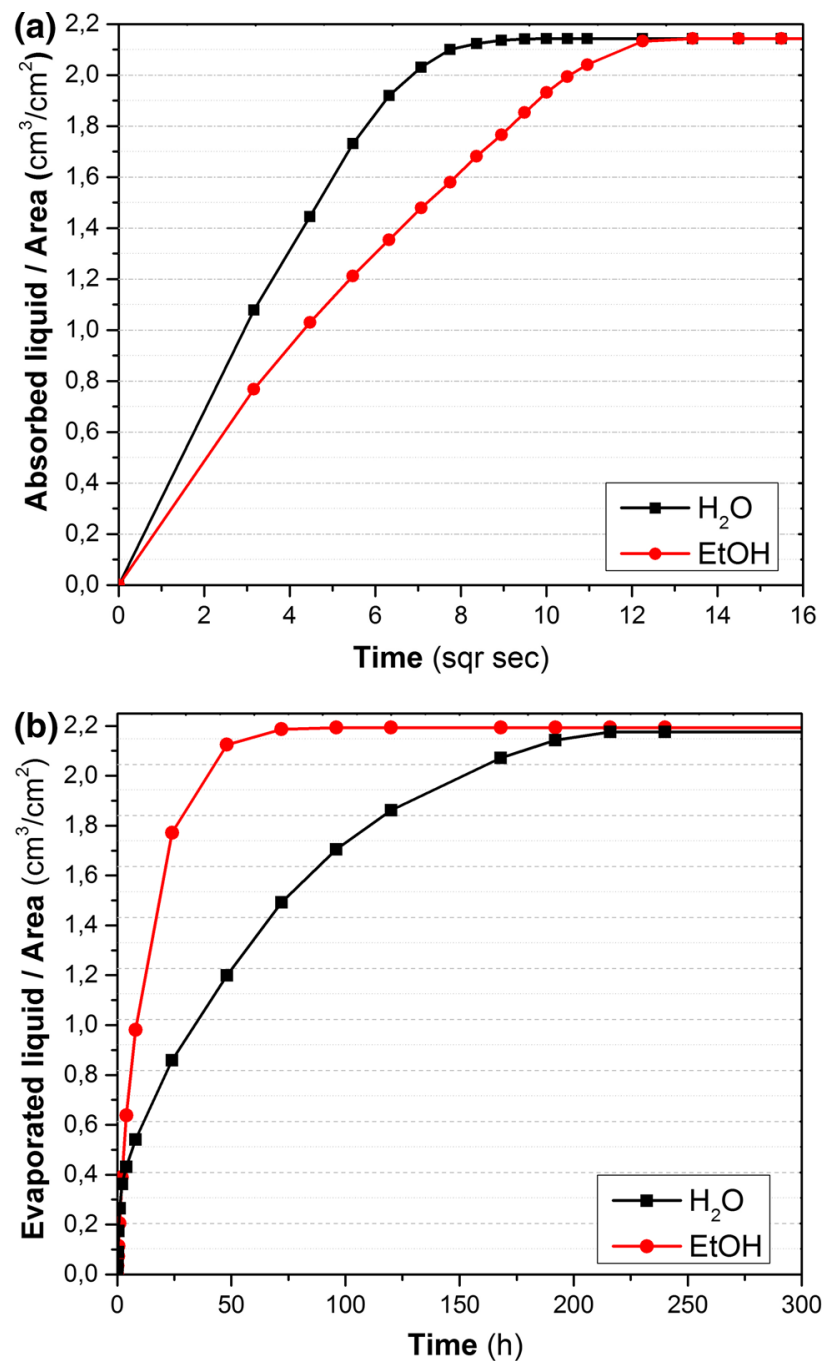

Fig. 3 a Absorption and $\mathbf{b}$ drying kinetics of water (black line) and ethanol (red line) on specimens of Maastricht limestone

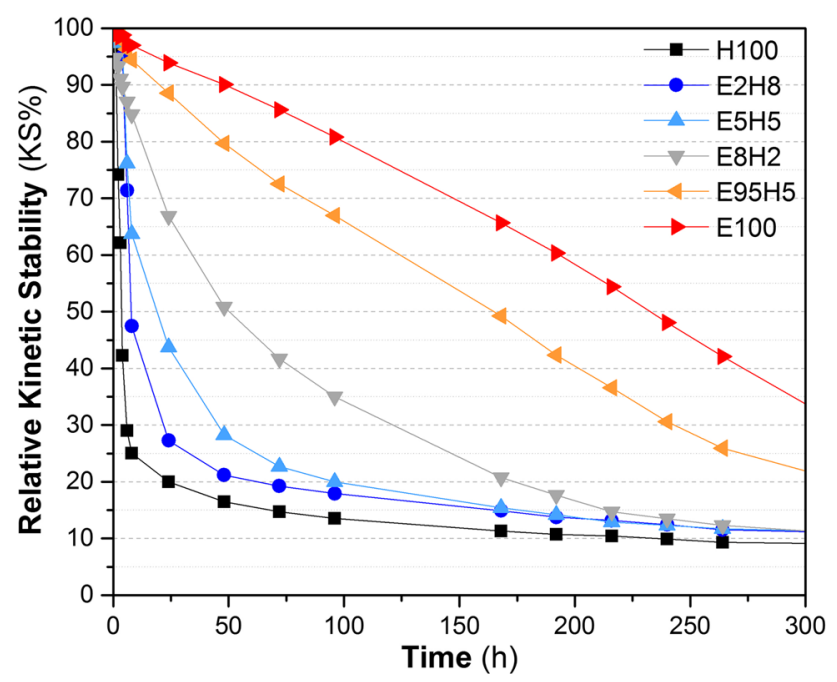

Fig. 4 Relative kinetic stability (KS \%) of the nanolimes over time collisions leading to aggregation of nanoparticles, which move around in random Brownian motions [34]: Sedimentation and particle aggregation are thus prevented [35].

When water is added to the ethanol-based dispersion, the kinetic stability significantly decreases. In the case of $\mathrm{E} 80 \mathrm{H} 20$ (20\% water), $\mathrm{KS} \%$ is still high at $8 \mathrm{~h}(84 \%)$, but it decreases to $66 \%$ at $24 \mathrm{~h}$ and to around $35 \%$ at $96 \mathrm{~h}$. When $5 \%$ in volume of water is added (E95H5), the KS \% of the dispersion is $80 \%$ at $48 \mathrm{~h}$, decreasing to $66 \%$ at $96 \mathrm{~h}$. Even a small amount of water is remarkably influencing the kinetic stability of the dispersion.

\subsection{Selection of the solvent}

Based on the results reported in Sect. 3.2, it can be concluded that:

- E100 has a very good stability, and it is known from previous research $[19,22]$ to easily penetrate in the Maastricht limestone.

- H100, H80E20 and H50E50 have a very low kinetic stability (see Fig. 4). This makes the handling of these nanolimes very difficult (nanolime should be used within short time from sonication); moreover, nanoparticle aggregation during absorption is expected. Because of these reasons, these nanolimes are not considered feasible alternatives and will not be further studied.

- E80H20 and E95H5 are expected to be stable enough to be absorbed within the substrate. Their lower kinetic stability in comparison to E100 might enhance precipitation of the nanoparticles at the end of the absorption process, and thereby limit back migration of nanoparticles to the surface.

Based on the above reported considerations, E80H20, E95H5 and, as comparison, E100, have been selected to be further studied.

\subsection{Assessment of nanoparticles deposition}

E80H20, E95H5 and, as comparison, E100, have been applied by capillary absorption on Maastricht limestone. The penetration of the nanoparticles immediately after absorption as well as their deposition after drying of the solvent has been studied.

\subsubsection{Phenolphthalein test}

The penetration of the nanoparticles immediately after saturation has been studied by phenolphthalein test. Figure 5 shows the cross-section of Maastricht limestone specimens, sprayed with a phenolphthalein solution 


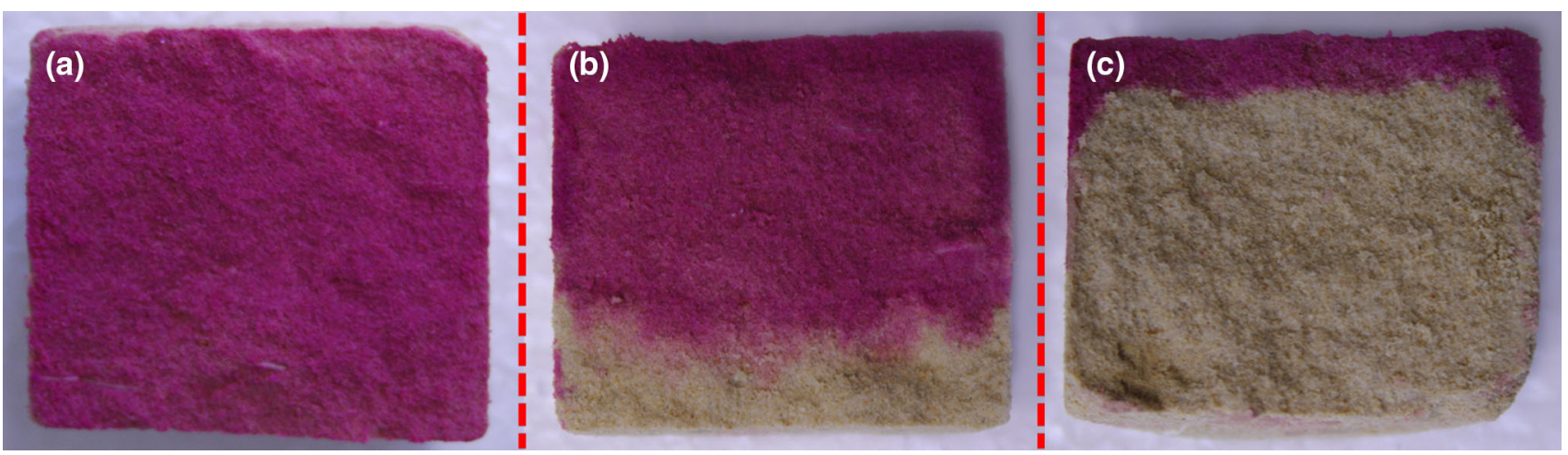

Fig. 5 Pictures of the phenolphthalein test performed on the crosssections of specimens of Maastricht limestone treated by capillary absorption until full saturation with E100 (a), E95H5 (b) and E80H20 (c). The drying surface (which was also the wetting surface) is on the top of the specimen

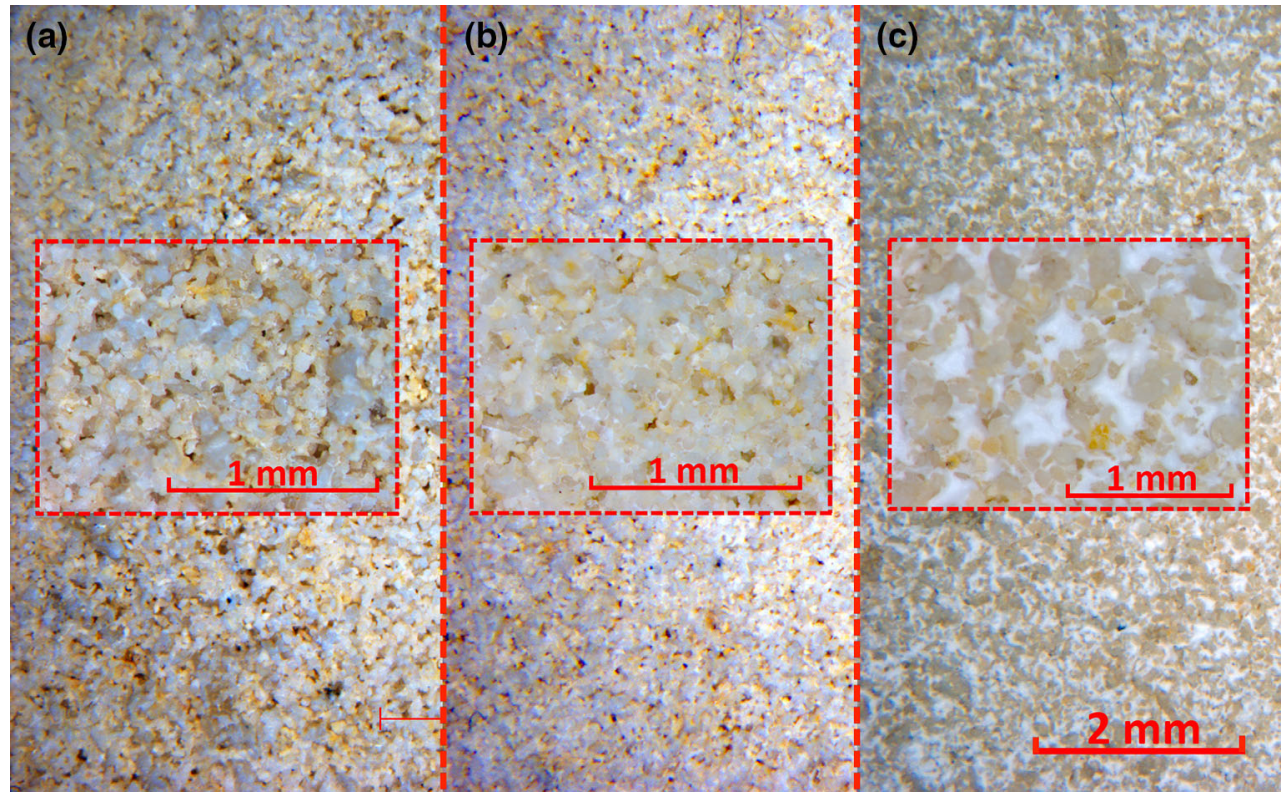

Fig. 6 Microphotographs of the drying surface of Maastricht limestone specimens treated with E100 (a), E95H5 (b) and E80H20 (c), and relative zoom on most significant spots

immediately after saturation, respectively, with E100, E95H5 and E80H20.

It can be observed that nanolime E100 homogenously penetrates within the limestone (Fig. 5a), saturating the entire section $(40 \mathrm{~mm})$ of the specimen.

E95H5 treatment guarantees as well a fast and proper penetration within the limestone (Fig. 5b), and no accumulation of nanoparticles at the absorption surface is observed; however, at $28-30 \mathrm{~mm}$ in depth, nanoparticles separate from the solvent (no purple color induced by the phenolphthalein is observed after that point), which flows further to saturate the entire section of the specimen. This can be explained by a partial aggregation of the lime nanoparticles within the porous network, during nanolime absorption.
In the case of E80H20, lime nanoparticles penetrate just in the first 5-7 mm in depth in the material (Fig. 5c); the low kinetic stability of the nanolime enhances nanoparticles-solvent phase separation, causing deposition near the absorption surface.

\subsubsection{Optical microscopy}

Maastricht limestone specimens treated with E100, E80H20 and E95H5 were analyzed by optical microscopy. When observing the absorption surfaces, it can be seen that E100 and E95H5 did not leave any white deposit at the surface (Fig. 6a, b). Conversely, some deposits of lime nanoparticles are observed with E80H20, which formed a whitish patina at the absorption surface (Fig. 6c). 

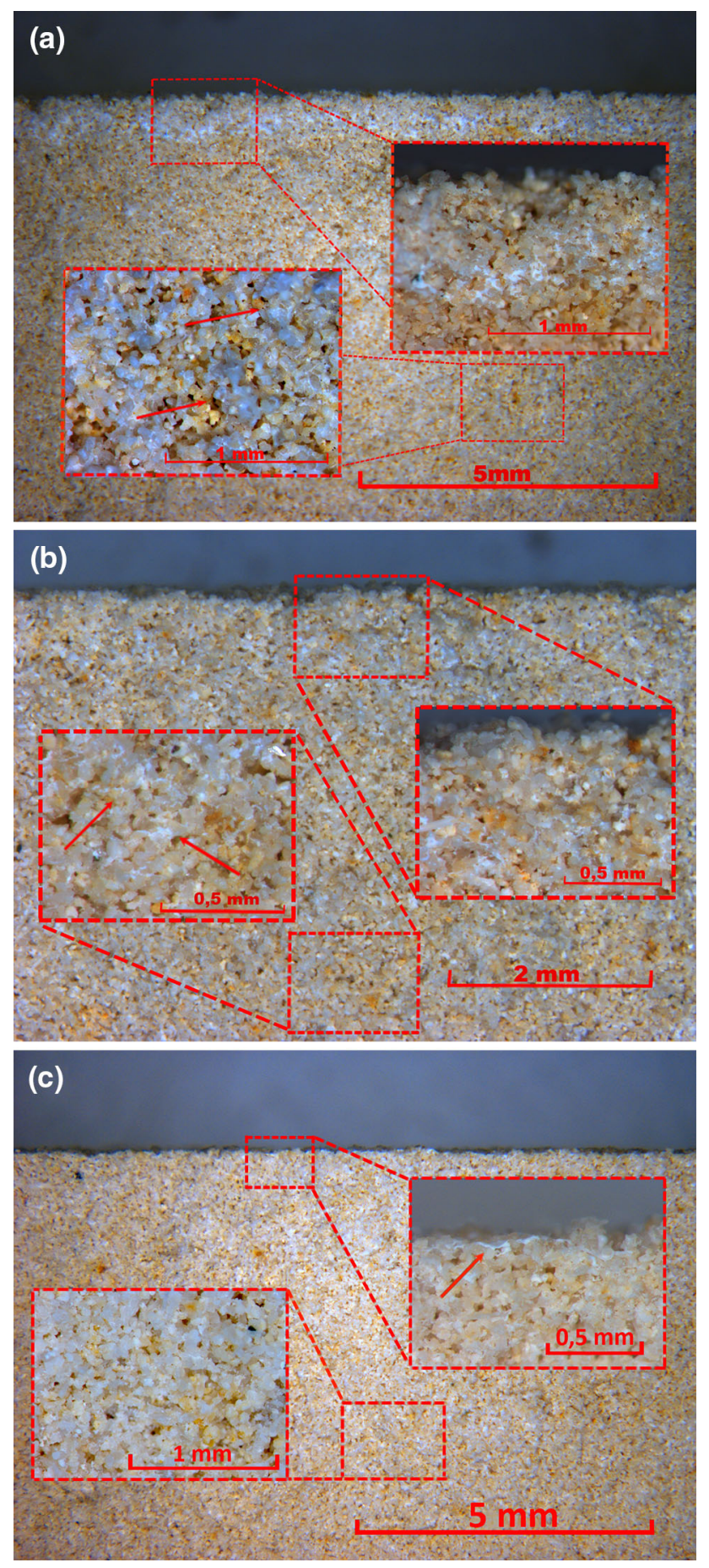

Fig. 7 Microphotographs of the cross-sections of the Maastricht limestone specimens treated with E100 (a), E95H5 (b) and E80H20 (c), and relative zoom on most significant spots. The arrows indicate the deposits of lime nanoparticles

When analyzing more in detail the cross-section of the treated limestone specimens, a layer $(0.1-0.2 \mathrm{~mm}$ thick) highly enriched in lime nanoparticles can be seen at $0.5 \mathrm{~mm}$ from the evaporation surface of the specimen treated with nanolime E100 (Fig. 7a). Clusters of lime nanoparticles are barely visible in depth in the specimen. As observed in a previous study [19], the high kinetic stability and evaporation rate of the ethanol-based nanolime can, in coarse porous stone, favor the migration of nanoparticles back to the surface during drying, causing an accumulation of nanolime just beneath the evaporation surface.

Differently, a more homogeneous in-depth distribution of the lime nanoparticles can be observed within the crosssection of Maastricht limestone treated with E95H5. Clusters of lime nanoparticles can be identified up to 18-20 mm from the absorption surface (Fig. 7b).

In the case of $\mathrm{E} 80 \mathrm{H} 20$, a deposit of lime nanoparticles can be observed at the absorption surface of the treated specimen (Fig. 7c). Sporadic and heterogeneously distributed clusters of nanolime are identified up to $6-8 \mathrm{~mm}$ in depth in the specimen, confirming the results obtained by phenolphthalein test.

On the basis of the optical microscopy results, it is can be concluded that E95H5 guarantees a deeper in-depth deposition of nanoparticles and it is thus a much better option than E80H20. Because of this reason, further SEM observations were only carried out on treatments with E95H5 and E100.

\subsubsection{SEM-EDS}

More detailed microstructural observations on the deposition of nanolime within the treated specimens were performed by SEM-EDS.

The SEM analysis of E100 treatment confirms a significant nanolime deposition nearby the drying surface, at $0.5 \mathrm{~mm}$ in depth (Fig. 8a). In fact, at this location agglomerated primary microclusters (generally with a size of 2-3 $\mu \mathrm{m}$ ) formed larger secondary nanolime deposits (up to $50 \mu \mathrm{m}$ in some cases). In addition, local depositions of lime nanoparticles are identified deeper in the cross-section: At $20 \mathrm{~mm}$ from the drying surface, sporadic clusters of nanolime particles are visible (Fig. 8b).

The SEM-EDS analysis of the limestone specimen treated with E95H5 shows nanolime deposits up to 25-27 mm in depth (Fig. 8d), more homogeneously distributed than in the case of E100; lime nanoparticles have a squared to hexagonal plate-like shape and dimensions ranging between 10 and $300 \mathrm{~nm}$, which mainly agglomerate in larger clusters. Nanolime deposition just beneath the surface (Fig. 8c) is much less than in the case of the specimen treated with E100, confirming the optical microscopy observations. Deeper in the specimens $(35-40 \mathrm{~mm})$, the presence of nanoparticles is limited, in accordance with the results obtained by phenolphthalein test. 

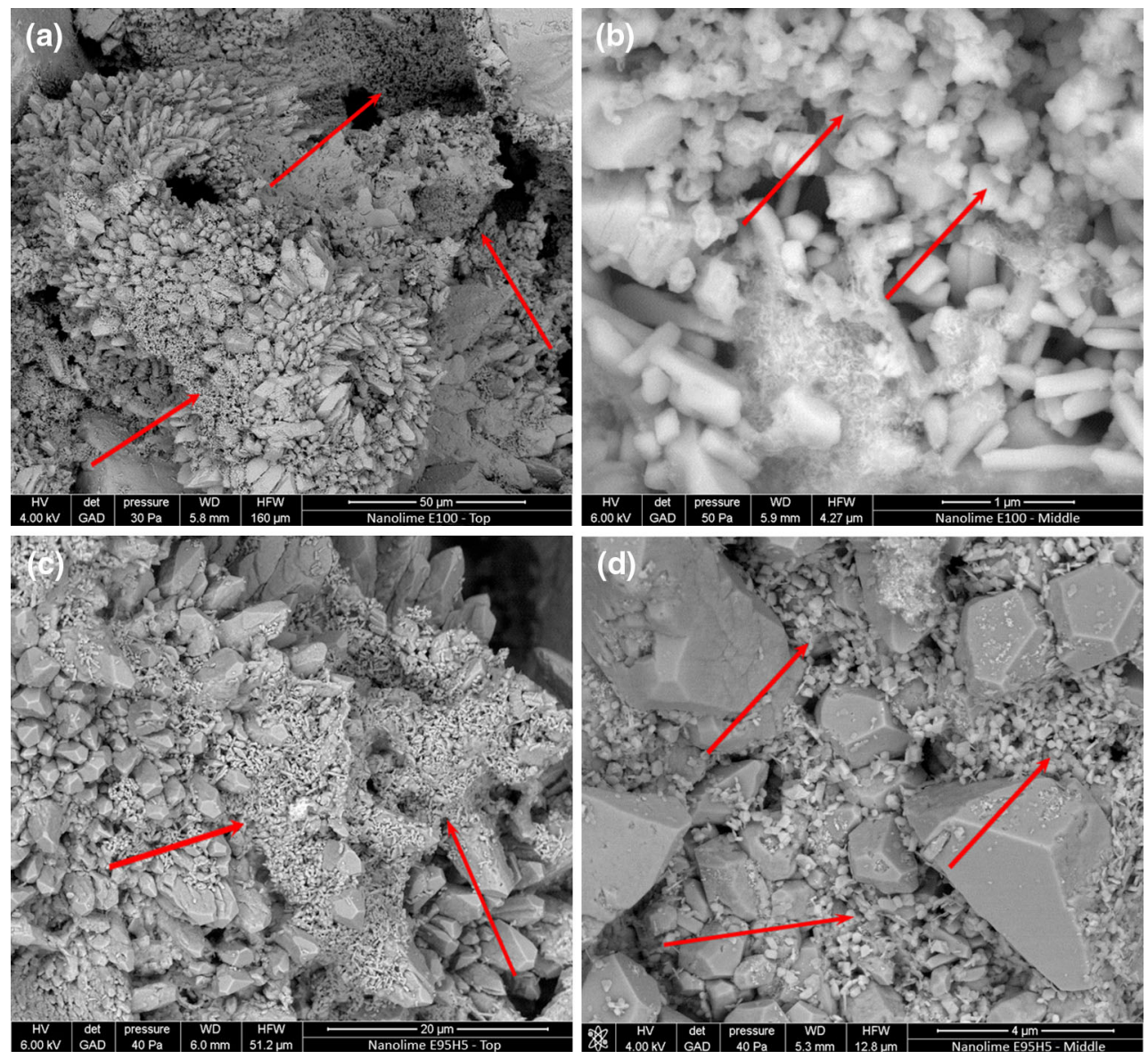

Fig. 8 SEM microphotographs of Maastricht limestone cross-sections after the treatment with E100 (a, b) and E95H5 (c, d). The images correspond to different deposition depths from the drying

surface: $0.4 \mathrm{~mm} \mathrm{(a);} 18 \mathrm{~mm}(\mathbf{b}) ; 0.5 \mathrm{~mm}(\mathbf{c})$ and $18 \mathrm{~mm}(\mathbf{d})$. The arrows indicate the deposits of lime nanoparticles

\section{Discussion and conclusions}

Previous research by the authors showed that very stable nanolime dispersions (dispersed in pure ethanol) may lead, in coarse porous substrates, to nanolime deposition near the surface, due to back migration of the nanoparticles during drying [19]. Based on these results, a model for the choice of suitable nanolime has been developed, relating the stability of nanolime dispersion to the moisture transport properties of the substrates [22]. According to this model, less stable dispersions would be more suitable for coarse substrates (i.e., with fast water absorption and drying), whereas very stable dispersions could be more successfully used on fine porous substrates. The stability of the nanolime dispersion can be modified by an appropriate choice of the solvent.

In this research, this model has been further developed and validated in the case of Maastricht limestone, a coarse porous limestone.

Newly synthesized nanolime particles were dispersed in different solvents: pure ethanol, pure water, and water-

ethanol mixtures with different ratios. The aim was to define the optimal solvent mixture, i.e., with a kinetic stability sufficient to guarantee a homogeneous absorption of the nanolime within the substrate but, at the same time, to avoid back migration of the particles to the surface during drying.

The results of the colloidal stability of the nanolimes showed that, as expected, ethanol-based dispersion (E100) have a very high kinetic stability. The addition of water, even in small amount, has been shown to remarkably reduce the stability. Nanolimes with more than $20 \%$ (in volume) of water were considered to be not sufficiently stable for the time needed to perform application.

Based on these results, ethanol-based nanolimes with $5 \%(\mathrm{E} 95 \mathrm{H} 5)$ and $20 \%(\mathrm{E} 80 \mathrm{H} 20)$ of water were selected and applied on Maastricht limestone. Nanolime E100 was applied as well for comparison.

Nanolime E100 showed a good penetration but also back migration of nanoparticles during drying, confirming previous results [19]. Nanolime E80H20 led to slight surface deposition of nanoparticles during the absorption 
phase; besides, separation of the nanoparticles from the solvent was observed during absorption. This suggests that this percentage of water is too high (i.e., too low kinetic stability of the nanolime) to guarantee proper absorption, even in a very coarse substrate as the Maastricht limestone.

Conversely, nanolime E95H5 showed a proper penetration during the absorption and, thanks to the lower kinetic stability of the dispersion in comparison to E100, back migration was limited and nanoparticles deposited in depth.

It can be concluded that coarse porous substrates, such as Maastricht limestone, can be optimally consolidated in depth by the use of a nanolime dispersed in ethanol and a limited amount of water $(5 \%)$. These results validate the model [22] and confirm that knowledge on moisture transport properties of the substrate is required for a successful in-depth consolidation treatment.

Research is ongoing to assess the consolidating effectiveness of the selected nanolime and to translate the results of this laboratory research, carried out by capillary absorption till full saturation of the specimens, to the practice, where other application methodologies (i.e., nebulization or brushing) are used. The final aim is to provide restorers and professionals in the field with guidelines for the choice and application of nanolime on calcareous substrates.

Acknowledgments The authors acknowledge Delft University of Technology and TNO (The Netherlands) for the financial support. Special thanks go to Timo Nijland, Willem Duvalois (TNO, The Netherlands) for SEM-EDS analysis.

Open Access This article is distributed under the terms of the Creative Commons Attribution 4.0 International License (http://crea tivecommons.org/licenses/by/4.0/), which permits unrestricted use, distribution, and reproduction in any medium, provided you give appropriate credit to the original author(s) and the source, provide a link to the Creative Commons license, and indicate if changes were made.

\section{References}

1. P. Baglioni, R. Giorgi, D. Chelazzi, in Progress in Cultural Heritage Preservation-4th International Conference, EuroMed 2012 (Lemessos, Cyprus, 2012), pp. 313-318

2. P. Fermo, G. Cappelletti, N. Cozzi, G. Padeletti, S. Kaciulis, M. Brucale, M. Merlini, Appl. Phys. A 116, 341 (2014)

3. G. Cappelletti, P. Fermo, M. Camiloni, Prog. Org. Coat. 78, 511 (2015)

4. L. Dei, B. Salvadori, J. Cult. Herit. 7, 110 (2006)

5. R. Giorgi, L. Dei, P. Baglioni, Stud. Conserv. 45, 154 (2000)

6. D. Chelazzi, G. Poggi, Y. Jaidar, N. Toccafondi, R. Giorgi, P. Baglioni, J. Colloid Interface Sci. 392, 42 (2013)

7. G. Ziegenbalg, K. Brummer, J. Pianski, in J. Válek, C. Groot, J. J. Hughes (eds.), Proceedings of the 2nd Historic Mortars Conference and RILEM TC 203-RHM Final Workshop-HMC10 (RILEM Publications, Prague, 2010), pp. 1301-1309
8. M. Ambrosi, L. Dei, R. Giorgi, C. Neto, P. Baglioni, Langmuir 17(14), 4251-4255 (2001)

9. C. Rodriguez-Navarro, A. Suzuki, E. Ruiz-Agudo, Langmuir 29(36), 11457-11470 (2013)

10. G. Poggi, N. Toccafondi, L.N. Melita, J.C. Knowles, L. Bozec, R. Giorgi, P. Baglioni, Appl. Phys. A 114, 685 (2014)

11. A.P.F. Pinto, J.D. Rodrigues, Stud. Conserv. 59(2), 79 (2012)

12. E. Hansen, E. Doehne, J. Fidler, J. Larson, B. Martin, M. Matteini, C. Rodrigues-Navarro, E. Sebastian Pardo, P. Price, A. de Tagle, J.M. Teutonico, N. Weiss, Rev. Conserv. 4, 13 (2003)

13. L. Toniolo, A. Paradisi, S. Goidanich, G. Pennati, Constr. Build. Mater. 25(4), 1553 (2010)

14. R.P.J. van Hees, B. Lubelli, T. Nijland, A. Bernardi, in 9th International Symposium on the Conservation of Monuments in the Mediterranean Basin-Monubasin 2014 (Ankara, Turkey, 2014). pp. 1-12

15. G. Borsoi, M. Tavares, R. Veiga, A. Santos, Silva. Microsc. Microanal. 18, 1181 (2012)

16. P. Baglioni, D. Chelazzi, R. Giorgi, G. Poggi, Langmuir 29, 5110 (2013)

17. A. Campbell, A. Hamilton, T. Stratford, S. Modestou, I. Ioannou, in Symposium Adhesive and Consolidants for Conservation: Research and Applications, ICC (Ottawa, Canada, 2011), pp. $1-16$

18. D. Costa, J. Delgado Rodrigues, Consolidation of a porous limestone with nanolime, in 12th International Congress on Deterioration and Conservation of Stone (Columbia University, New York, 2012), pp. 9-20

19. G. Borsoi, B. Lubelli, R. van Hees, R. Veiga, A. Santos, Silva. J. Cult. Herit. 18, 242 (2016)

20. S.A. Ruffolo, M.F. Russa, P. Aloise, C.M. Belfiore, A. Macchia, A. Pezzino, G.M. Crisci, Appl. Phys. A 114(3), 753 (2013)

21. E. Ghaffari, T. Koberle, J. Weber, in 12th International Congress on Deterioration and Conservation of Stone (Columbia University, New York, 2012), pp. 17-21

22. G. Borsoi, B. Lubelli, R. van Hees, R. Veiga, A. Santos Silva, L. Colla, Colloid Surface A 497, 171 (2016)

23. R. Dreesen, M. Dusar, Mater. Charact. 53, 273 (2004)

24. T.G. Nijland, C.W. Dubelaar, H.J. Tolboom, R.P.J. van Hees, in Heritage, Weathering and Conservation Conference-HWC 2006, Madrid (Taylor \& Francis, London, 2006), pp. 15-21

25. C.W. Dubelaar, M. Dusar, R. Dreesen, W.M. Felder, T.G. Nijland, in Heritage, Weathering and Conservation Conference HWC 2006, Madrid (Taylor \& Francis, London, 2006), pp. 9-14

26. R.P.J. van Hees, T. Nijland, Heron 54(4), 227 (2009)

27. EN 15801, European Standard. Conservation of Cultural Heritage-Test Methods-Determination of water absorption by capillarity (European Committee for Standardization-CEN, 2009)

28. EN 16322, European Standard. Conservation of Cultural Heritage-Test Methods-Determination of drying properties (European Committee for Standardization-CEN, 2013)

29. Thermophysical Data in the Dortmund Data Bank Dortmund Data Bank Software \& Separation Technology (DDBST), http://www. ddbst.com/en/EED/Explorer\%20Edition\%20Data.php. Accessed 19 Apr 2016

30. J. Lahdensivu, Cem. Concr. Compos. 65, 29 (2016)

31. P. López-Arce, L.S. Gómez-Villalba, S. Martínez-Ramírez, M. Álvarez de Buergo, R. Fort, Powder Technol. 205(1-3), 263 (2011)

32. M. Licchelli, M. Malagodi, M. Weththimuni, C. Zanchi, Appl. Phys. A 114, 673 (2014)

33. C. Rodriguez-Navarro, E. Ruiz-Agudo, M. Ortega-Huertas, E. Hansen, Langmuir 21(24), 10948 (2005) 
34. C. Felix, A. Yaroshchuk, S. Pasupathi, B.G. Pollet, M.P. Bondarenko, V.I. Kovalchuk, E.K. Zholkovskiy, Adv. Colloid Interface Sci. 211, 77 (2014)
35. L. Zheng, B. Li, P. Lin, X. Zhang, C. Zhang, B. Zhao, T. Wang, Microfluid. Nanofluid. 15, 11 (2013) 